\title{
USO DE AGROTÓXICO OU CONTROLE AGROECOLÓGICO DE PRAGAS E DOENÇAS DA AGRICULTURA? UMA REFLEXÃO A PARTIR DO MUNICÍPIO DE ALVORADA DO GURGUÉIA-PI
}

\section{PESTICIDE USE OR AGROECOLOGICAL CONTROL OF \\ AGRICULTURAL PESTS AND DISEASES? A REFLECTION FROM THE MUNICIPALITY OF ALVORADA DO GURGUÉIA-PI}

\author{
Francisca Herilene Oliveira ${ }^{1}$, Valcilene Rodrigues da Silva ${ }^{2}$
}

\begin{abstract}
${ }^{1}$ Licenciada em Educação do Campo na área de Ciências Humanas e Sociais pela Universidade Federal do Piauí, campus Professora Cinobelina Elvas. ${ }^{2}$ Professora da Licenciatura em Educação do Campo na Universidade Federal do Piauí. Integrante do Núcleo de Educação, Pesquisa e Práticas em Agroecologia e Geografia (NEPPAGUFPE) e do Núcleo de Agroecologia do Vale do Gurgueia (NAGU/UFPI).
\end{abstract}

DOI: https://doi.org/10.52719/bjas.v1i2.2925

\section{RESUMO}

Objetivou-se com a pesquisa analisar a percepção dos agricultores de Alvorada do Gurguéia em relação ao controle de pragas e doenças das plantações, bem como os impactos e consequências das formas de controle usadas. Para isso, utilizamos a revisão bibliográfica e trabalho de campo em que foram realizadas nove entrevistas. Os resultados da pesquisa evidenciam que boa parte dos agricultores passaram a usar defensivos e fertilizantes químicos em Alvorada do Gurguéia após a chegada de um projeto para agricultura irrigada. No entanto, tais agricultores desejam alguma alternativa para substituir o uso de agrotóxicos em virtude dos impactos já percebidos no município. As discussões levam à conclusão de que apesar do investimento do capital e dos pacotes tecnológicos é possível resistir e fazer uma agricultura que considere os saberes, as culturas dos povos e os princípios da natureza. A agroecologia é posta como uma alternativa sustentável não somente para o combate de pragas e doenças da agricultura, mas para todo o sistema produtivo e social.

Palavras-Chave: Agroecologia. Manejo agroecológico. Vale do Gurguéia

\section{ABSTRACT}

The objective of this research was to analyze the perception of farmers of Alvorada do Gurguéia regarding the control of plantation pests and diseases, as well as the impacts and consequences of the control forms used. For this we used the literature review and field work in which nine interviews were conducted. The survey results show that most farmers started using pesticides and chemical fertilizers in Alvorada do Gurguéia after the arrival of a project for irrigated agriculture. However, such farmers want some alternative to replace the use of 

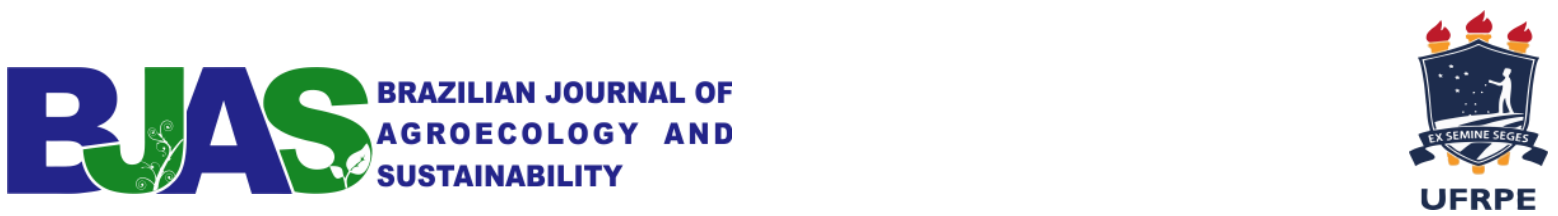

pesticides due to the impacts already perceived in the municipality. The discussions lead to the conclusion that despite the investment of the capital and the technology packages it is possible to resist and make an agriculture that considers the knowledge, the cultures of the peoples and the principles of nature. Agroecology is presented as a sustainable alternative not only for the fight against pests and diseases of agriculture, but for the whole productive and social system.

Keywords: Agroecology. Agroecological management. Vale do Gurguéia.

\section{INTRODUÇÃO}

Estima-se que a agricultura tenha em torno de 10 mil anos e vêm passando por diversas mudanças ao longo do tempo tendo em vista os fatores ambientais e o modo como a sociedade foi se relacionando com a natureza. Alguns autores falam em períodos de verdadeiras revoluções agrícolas. De acordo com Paulo Petersen uma primeira revolução envolveu mudanças na gestão da fertilidade dos solos mediante o encurtamento do tempo dos pousios e, finalmente, a sua completa supressão, a adoção de sistemas alternativos de manejo da biomassa, viabilizados pela introdução de adubos verdes e plantas forrageiras, e a maior integração ecológica entre a lavoura e a pecuária (Petersen, 2012).

O autor explica que até o final do século XIX, os agricultores desenvolviam estratégias técnicas para a gestão da fertilidade com base no manejo da biomassa localmente produzida. Porém, essas dinâmicas de interdependência e mútua transformação entre as técnicas e os ecossistemas foram profundamente alteradas com o surgimento dos fertilizantes sintéticos. A descoberta dos fertilizantes químicos abriu caminho para que o desenvolvimento tecnológico na agricultura tomasse o rumo da agroquímica, permitindo o paulatino abandono das práticas orgânicas de recomposição da fertilidade. Configuraram-se assim as condições necessárias para a disseminação das monoculturas em substituição às agriculturas diversificadas, ajustadas às especificidades ecológicas locais, e os avanços posteriores nos campos da mecanização e da genética agrícola, o que veio a ser chamada de Revolução Verde $^{1}$ ou Segunda Revolução agrícola.

\footnotetext{
${ }^{1}$ A revolução verde foi um processo que se deu a partir da busca por uma produção em larga escala com início na década de 1950, em vários países do mundo, e entre os anos 1960 e 1970 no Brasil. Um ciclo de inovações tecnológicas adquiridas com os avanços do pós-guerra iniciou-se a partir de então, por meio de uma tecnologia de controle da natureza de base cientifico-industrial, sob o pretexto de acabar com a fome no mundo. A Revolução Verde é composta com os pacotes tecnológicos, ou seja, insumos químicos, sementes de laboratório, irrigação, mecanização grandes extensões de terra, conjugado ao difusionismo tecnológico, bem como uma base ideológica de valorização do progresso. (PEREIRA, 2010 p. 687).
} 

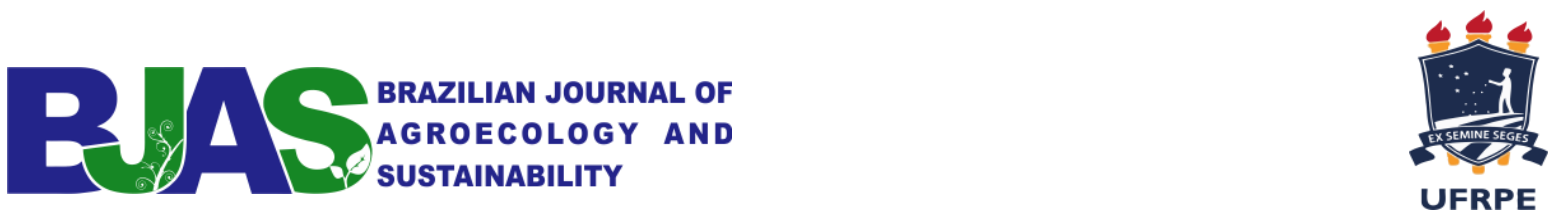

Uma grave consequência da Revolução Verde foi a ocupação da paisagem agrícola com monoculturas, isso resultou na multiplicação no número de insetos-praga e de organismos patogênicos, abrindo a frente de inovação em direção aos agrotóxicos. Raquel Rigotto afirma que historicamente agricultores e agricultoras desenvolvem maneiras de lidar com insetos, plantas e outros seres vivos que se difundem nos cultivos (Rigotto, 2010). No entanto, a Revolução Verde disseminou globalmente um novo regime tecnológico baseado na dependência da agricultura em relação à indústria e ao capital financeiro (Petersen, 2012) e com isso muitos agricultores abandonaram suas práticas tradicionais aderindo os pacotes tecnológicos.

Trazendo essa realidade para o contexto da área estudada, observa-se no Sul do Piauí cada vez mais adesão à lógica do capital e a modificação do jeito de fazer agricultura, principalmente com a implantação das monoculturas de soja na região. Uma situação preocupante é que essa lógica não é aderida somente pelos sojicultores. O uso de agrotóxicos se torna cada vez mais frequente, o que pode ser justificado por vários motivos, dentre eles, a lógica do capital que vem tentando adentrar na vida dos agricultores mesmo aqueles que produzem em pequena escala; segundo, porque muitos desconhecem maneiras alternativas de manter sua plantação segura ou porque mesmo conhecendo aderem a esse recurso devido a praticidade (Palma, 2011). Assim, a pesquisa teve por objetivo analisar a percepção dos agricultores de Alvorada do Gurguéia em relação ao controle de pragas e doenças das plantações, bem como os impactos e consequências das formas de controle usadas por esses agricultores. O artigo é resultado do trabalho de conclusão de curso da primeira autora e a motivação pessoal para estudar a problemática quanto ao uso de agrotóxicos e compreender como os agricultores de Alvorada do Gurguéia lidam com o surgimento de pragas e doenças em suas plantações, surgiu a partir de um caso de intoxicação pela utilização de agrotóxicos que levou a óbito um membro familiar.

Do ponto de vista metodológico a pesquisa é qualitativa. Para isso utilizou-se a revisão bibliográfica e trabalho de campo em que foram realizadas nove entrevistas abertas com agricultores e funcionários do DNOCS. As propriedades foram escolhidas aleatoriamente e as entrevistas aconteciam de acordo com a disponibilidade da família para participar. A entrevista buscou respostas sobre o modo de produção, os principais cultivos, o manejo desenvolvido para o combate de pragas e doenças, bem como a percepção dos agricultores em relação aos riscos à saúde em decorrência do contato com os agrotóxicos e aos riscos ambientais.

Alvorada do Gurguéia é um município pequeno do sul piauiense com uma população estimada em 5.419 pessoas para 2019 (Instituto Brasileiro de Geografia e Estatística [IBGE], 

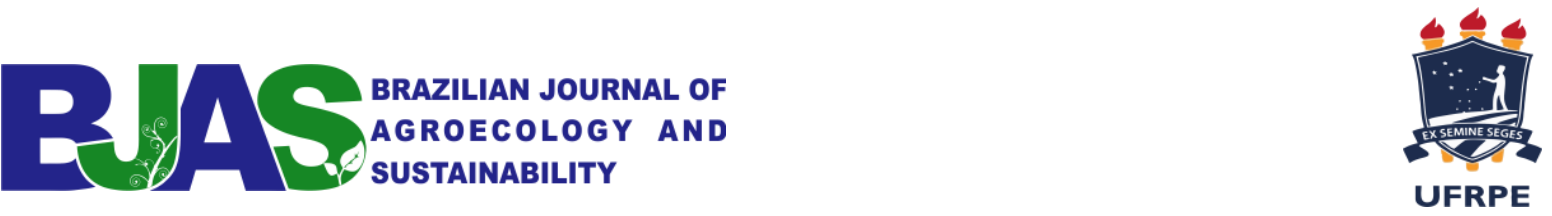

2019). Não muito diferente de outros municípios da região, a agricultura é a principal fonte de renda das famílias. A origem do município já se deu em função da agricultura quando ainda pertencia ao território de Cristino Castro e implantou-se um projeto pelo Departamento Nacional de Obras Contra as Secas (DNOCS) voltado para a agricultura irrigada. O povoado que ganhou o mesmo nome DNOCS nasceu em 1978 e foi elevado à categoria de município após 16 anos com a lei estadual de número 4.680 de 26 de janeiro de 1994. De acordo com o IBGE (2019), 62,2\% das famílias residem na zona rural, mas a agricultura é a principal fonte de trabalho mesmo para os sujeitos que residem na cidade, pois se deslocam para o campo diariamente.

\section{A ENTRADA DOS AgROTÓXICOS NOS CULTIVOS E AS CONSEQUENCIAS GERADAS}

Quando pensamos na expansão da utilização de agrotóxicos no Brasil logo associamos a expansão do agronegócio. De acordo com Cara (2009) a partir de 1960, com a implementação da indústria pesada no país [..] tem início o processo de modernização da agricultura, quando são implantadas as fábricas de maquinários e insumos agrícolas, esse processo de fixação dessas indústrias siderúrgicas, de material elétrico, petroquímicas etc. também veio com a intensão de facilitar e formar um novo mercado de consumo para novos produtos industriais.

Tais indústrias precisavam ter quem consumisse seus produtos, e o Estado teve um papel importante nessa história, o de apoiar, incentivar e facilitar as formas para adquirir esses novos recursos de produção originários do novo ramo industrial. Apoio que beneficiou as indústrias nacionais e internacionais que se estabeleceram no país a partir de 1960, levando a uma rápida incorporação de modernas tecnologias na agricultura com o objetivo de aumentar a produção agrícola. (Cara, 2009).

Ainda de acordo com a autora a forma como se deu a modernização da agricultura no país ocasionou "a devastação das florestas, perda da fertilidade e contaminação do solo devido a sucessivas aplicações de herbicidas e fertilizantes químicos, assoreamento dos rios e diminuição da biodiversidade com a implantação da monocultura. (Cara, 2009, p. 128).

Nota-se que além de impactar diretamente o meio ambiente em decorrência das novas tendências de ocupação do solo, a modernização da agricultura acarretou uma série de mudanças no estilo de vida das comunidades locais, afetando a agricultura camponesa e intensificando o êxodo rural (Rufo, 2013). 

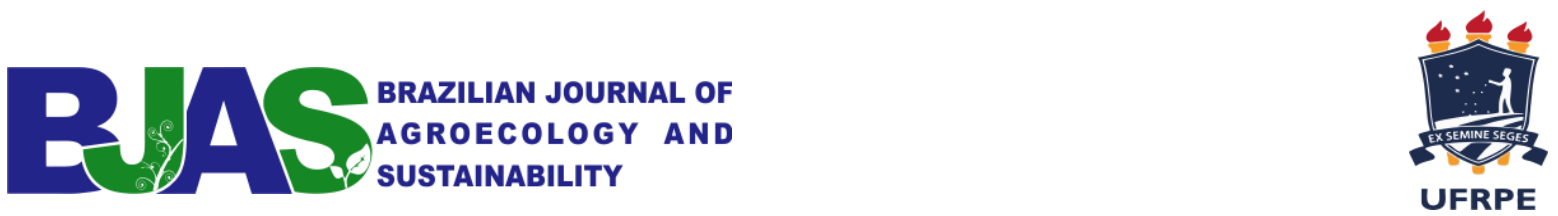

No caso do Piauí, o autor afirma que a modernização agrícola teve início na década de 1970 e intensificado na década de 1990 a partir da migração dos sulistas, do Rio Grande do Sul e Paraná, para o sudoeste piauiense. Tal migração foi motivada pelos grandes incentivos governamentais e o clima que favorecia o plantio de grãos, tendo como carro chefe a soja, voltada para a exportação.

Com a migração sulista para outras áreas do país observa-se grande ocupação de porções territoriais dos estados do Maranhão, Tocantins, Piauí e Bahia, constituindo-se em 2015 a última fronteira agrícola do Brasil - o MAPITOBA ${ }^{2}$ que teve como objetivo a incorporação de novas áreas no cenário de produção moderna da agricultura visando o aumento da produção do país na área de commodities de grãos, especialmente a soja e milho.

Atualmente, esse processo de modernização como o Matopiba está incluso na tendência internacional e nacional de modernização da produção sendo elas consequências do processo de globalização e do capitalismo para atender às demandas hegemônicas, sobretudo da produção de commodities agrícolas e do controle de terras pelo capital financeiro (Spadotto \& Cogueto, 2019, p. 214). Ou seja, não se trata mais de sulistas ocupando áreas do MATOPIBA, mas disputas territoriais de proporções internacionais.

De acordo com Rufo (2013) a agricultura moderna impôs uma série de mudanças e novos contextos na realidade piauiense, dentre elas destaca-se a dinamização econômica do surgimento de novas centralidades urbanas, assim como o desenvolvimento de equipamentos de serviços rurais e urbanos. Entretanto, todo esse processo de modernização se expõe de forma contraditória, ao mesmo tempo que se mostra impulsionar a economia da região, e uma visibilidade nacional e internacional, também impacta negativamente as cidades, o meio ambiente e as comunidades locais.

A realidade do município de Alvorada está totalmente dentro dessa lógica de modernização da agricultura e adesão dos pacotes tecnológicos sem considerar a realidade de cada lugar e da cultura das pessoas. Nesse sentido, questiona-se sobre que modernização é que não melhora as condições de vida dos agricultores e contribui com diversos impactos ambientais como o desmatamento, a poluição e impactos na saúde, principalmente pelo uso de

\footnotetext{
${ }^{2}$ MATOPIBA palavra formada com as iniciais dos estados do Maranhão, Tocantins, Piauí e Bahia, onde acontece exploração de terras do cerrado para produção de monocultivos em alta escala pelo agronegócio. Segundo Souza e Pereira (2019) o MATOPIBA configura-se como um espaço de grandes expectativas para ganhos com valorização fundiária, onde as corporações podem adquirir as propriedades a baixo custo e rapidamente criar mecanismo de valorização das terras, através de uma produção agrícola altamente tecnificada e capitalizada, visto que os preços das terras no MATOPIBA são em geral ainda mais baixos que os praticados nas regiões agrícolas consolidadas do Centro Oeste, Sudeste e Sul do Brasil. Entre as empresas que atuam na exploração do mercado de terras no MATOPIBA destacamos a Brasil Agro, SLC Agrícola, Radar S/A, Adecoagro, Sollus Capital, entre outras. (SOUZA E PEREIRA, 2019, p. 28).
} 

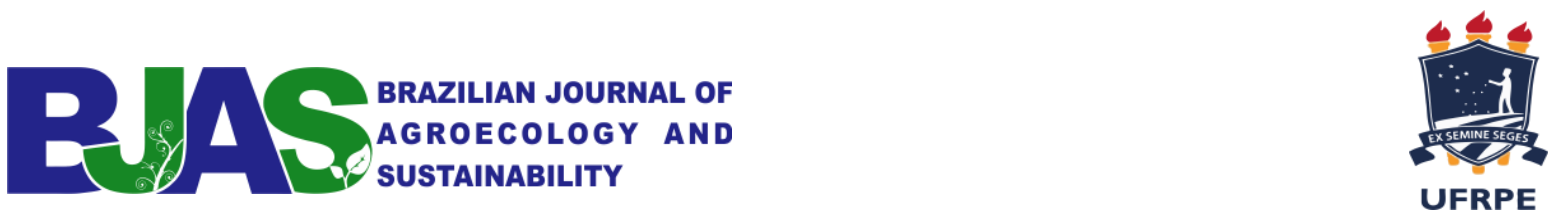

agrotóxicos? Questiona-se ainda sobre as políticas públicas e a legislação que estão sempre em benefícios de uns em detrimento de outros, a exemplo da legislação para o uso dos agrotóxicos. A lei dos agrotóxicos (Brasil, 1989) definem essas substâncias como:

\begin{abstract}
Os produtos e os agente de processo físicos, químicos ou biológicos, destinados ao uso nos setores de produção, no armazenamento e beneficiamento de produtos agrícolas, nas pastagens, na proteção de florestas, nativas ou implantadas, e de outros ecossistemas e também de ambientes urbanos hídricos e industriais, cuja finalidade seja alterar a composição da flora ou da fauna, afim de preservá-las da ação danosa de seres vivos considerados nocivos. (Brasil, 1989).
\end{abstract}

A lei trata do termo agrotóxico como algo que vem para proteger e preservar, mas os dados mostram que o uso de agrotóxicos traz muito mais malefícios que benefícios como será apresentado mais adiante.

Sabe-se que o consumo excessivo de agrotóxicos está fortemente ligado ao capital. O dossiê da Abrasco aponta que no período entre o segundo semestre de 2010 e o primeiro semestre de 2011, o mercado nacional de venda de agrotóxicos movimentou 936 mil toneladas de produtos das quais 833 mil foram produzidas no país e 246 mil toneladas importadas (Carneiro, 2015).

O Brasil está dominado pelo capital internacional que encontrou na agricultura formas de se produzir, seja pela concentração de terras ou pela inserção de tecnologias como máquinas, sementes transgênicas e agrotóxicos (Pereira \& Sousa, 2016). Exemplo disso é que $92 \%$ dos agrotóxicos comercializados no Brasil em 2010 foram produzidos por empresas de capital estrangeiro: Syngenta (Suíça), Dupont (Estados Unidos), Dow CHemical (Estados Unidos) [...] (Bombardi, 2012).

Quando analisa os estados, Bombardi (2017) aponta que o Piauí no ano de 2012 vendeu 11.026 toneladas de agrotóxicos ocupando o décimo primeiro lugar em uma escala de venda desses agrotóxicos e fertilizantes químicos por estado, tendo um aumento de 32,14\% entre os anos de 2010 e 2012. Quando analisa o uso de agrotóxicos por estabelecimentos agrícolas por municípios, a autora destaca os 5 primeiros municípios piauienses que mais consumiu agrotóxicos são Joaquim Pires, Caraúbas do Piauí, São José do Divino, Colônia do Gurguéia, São Gonçalo do Gurguéia. A maior parte desse uso é em função da soja. Ainda de acordo com a autora, a soja, atualmente ocupa mais de 30 milhões de hectares do solo brasileiro, ou seja, ocupa sozinha mais da metade $(52 \%)$ do volume de agrotóxicos comercializados no país. Consequentemente, esse elevado nível de consumo de agrotóxico fortalece cada vez mais o interesse das empresas estrangeiras no Brasil (Pereira \& Sousa, 2016).

Como ressalta Bombardi (2017) os dez ingredientes ativos mais vendidos no Brasil, dois são proibidos na União Europeia. Dados trazidos pela autora evidenciam a quantidade de 

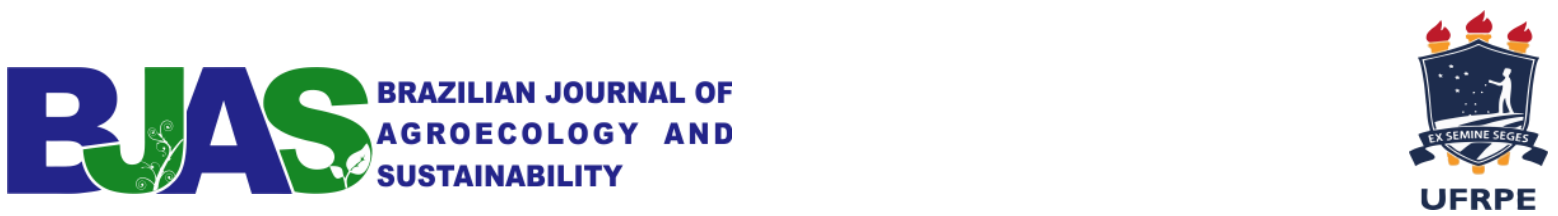

agrotóxicos que são autorizados em culturas como soja, café e de cítricos. Para o cultivo do café, são autorizados 121 diferentes tipos de agrotóxicos, porém 30 deles são proibidos na União Europeia. No caso da soja 150 agrotóxicos são autorizados para o seu cultivo, destes 35 estão proibidos na União Europeia. Já para os citros existem 116 agrotóxicos em que é permitido o uso para o cultivo, mas, 33 são proibidos na União Europeia.

Se esses dados são alarmantes, vale destacar que em 2019, com a última aprovação (Ato n 70 de 2 de outubro de 2019) para registros de agrotóxicos o governo federal brasileiro já somava um montante de 382 substâncias aprovadas, tornando-se o governo que mais aprovou a liberação de agrotóxicos no país.

O uso intensivo desses agrotóxicos vem provocando impactos significativos para a produção agrícola, mas também para a saúde do ser humano e do meio ambiente.

Sabe-se que existem inúmeras formas de contaminação com o agrotóxico. Após a aplicação nos cultivos, por exemplo, o solo absorve parte do veneno e acaba por contaminar os lenções freáticos. A contaminação também pode ocorrer de forma indireta. As crianças pequenas que permanecem no chão ou solo e que colocam as mãos e objetos na boca, podem estar sujeitas a exposição. Os pais expostos de forma ocupacional podem trazer agrotóxicos para casa nas roupas e equipamentos, aumentando o risco de adoecimento dos filhos e o risco aumenta também de acordo com o grau de exposição das mães durante a gravidez (Curvo, Pignati \& Pignatti, 2013).

De acordo com dados do Instituto Nacional do Câncer (INCA, 2015) a exposição ao agrotóxico pode ocorrer através da inalação, durante a aplicação e/ou preparo da substância química, contato com a pele ou oral durante a manipulação. As pessoas que estão dentro de uma probabilidade maior de contaminação são: trabalhadores agrícolas ou pecuaristas, trabalhadores de comércio e transporte de agrotóxicos e empregados de indústrias de composição destes defensivos químicos. A exposição também pode ocorrer através da pulverização de áreas que facilitem que o produto seja disperso pelo meio ambiente, assim contaminando áreas e atingindo a população; pelo consumo de água e alimentos contaminados e o contato com as roupas com as quais os trabalhadores estavam em contato com o agrotóxico.

Do mesmo modo, o dossiê da Abrasco afirma que também é possível ocorrer intoxicação através do leite materno:

Parte dos agrotóxicos utilizados tem a capacidade de dispersar no ambiente, e outra parte pode se acumular no organismo humano, inclusive no leite materno. O consumo do leite contaminado pode provocar agravos à saúde dos recém-nascidos, por sua vulnerabilidade à exposição a agentes químicos presentes no ambiente, por suas características fisiológicas e por se alimentarem quase exclusivamente com o leite materno até os 6 meses de idade. (Carneiro, 2015). 


\section{RAAS}

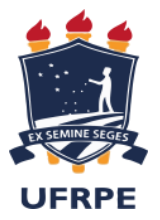

Essa situação é preocupante pois nem as crianças recém-nascidas estão isentas da contaminação do agrotóxico. O que se presume ser a forma mais segura e eficaz para proporcionar todos os nutrientes necessários para a criança e gerar um início de vida saudável - o leite materno, pode estar sendo contaminado e deixando as crianças vulneráveis a adquirir possíveis problemas de saúde.

De acordo com o INCA (2018), os efeitos do contato dessas substâncias químicas com o corpo podem durar segundos ou podem tornar-se crônicos, se a exposição ao agrotóxico acontecer de forma repetida a pequenas quantidades.

Quando se trata de contaminação, vale ressaltar que não somente os agricultores do campo estão sujeitos a contaminação pelo uso de agrotóxico. “As pessoas do meio urbano também se encontram sob risco, devido a contaminação ambiental e dos alimentos." (Palma, 2011, p. 20).

Sobre isso Carneiro (2015) apresenta que um terço dos alimentos consumidos cotidianamente pelos brasileiros está contaminado pelos agrotóxicos. De acordo com a investigação realizada pelo Programa de Análise de Resíduos de Agrotóxico (PARA) da Anvisa (2013-2015), 19,7\% das amostras apresentavam quantidades de substâncias químicas acima do limite máximo permitido. Dentre os principais alimentos contaminados destacam-se o abacaxi, alface arroz, beterraba, cebola, cenoura, couve, feijão, laranja, maçã, mamão, manga, morango, pepino, pimentão, repolho e tomate. O pimentão foi campeão, 91,8\% das amostras estavam contaminadas com níveis insatisfatórios na pesquisa realizada (Anvisa, 2016).

Bombardi (2012, p.1) enfatiza a gravidade do problema "no período de 1999 a 2009 houve 62 mil intoxicações por agrotóxico de uso agrícola no país; isto significa 5.600 intoxicações por ano ou 155,5 por dia ou uma a cada 90 minutos”. Muitas vezes direta ou indiretamente a contaminação da população por agrotóxico está relacionada ao descarte inadequado das embalagens.

Diante do exposto, vale destacar que existe um fórum para tratar do combate ao uso de agrotóxico, o Fórum Nacional de Combate aos Efeitos dos Agrotóxicos na Saúde e no Meio Ambiente. $\mathrm{O}$ fórum foi criado com o intuito de funcionar como uma ferramenta social e reúne membros de organizações governamentais e não governamentais como: sindicatos, universidades, associações profissionais e o Ministério Público do Trabalho (Carneiro, 2015).

Ainda de acordo com a Abrasco, o fórum possibilita promoção de articulação entre sociedade civil e os governos para o confronto aos efeitos nocivos dos agrotóxicos a saúde do consumidor, trabalhador e do meio ambiente. "Por seu intermédio o Ministério do Trabalho 

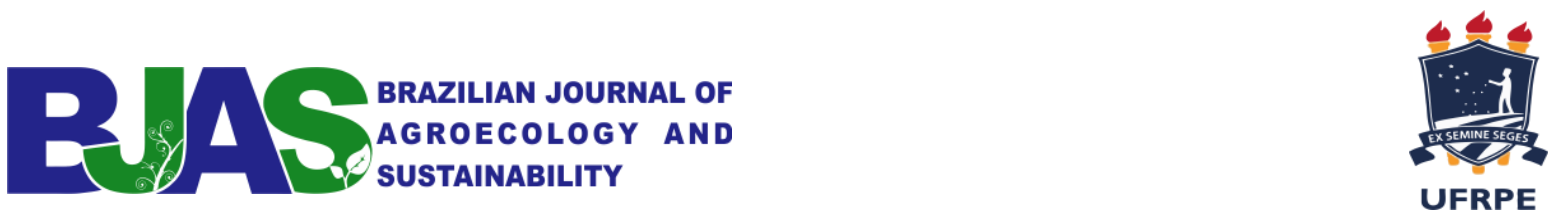

realiza, entre outras atividades, audiências públicas e investigações, e firma Termos de Ajustes de conduta (TAC) para a redução e restrição do uso de agrotóxico". (Carneiro, 2015, p. 189).

Assim percebe-se que vários setores da sociedade estão preocupados com essa problemática. E se antes se questionava os estudos sobre os agrotóxicos, o Dossiê da Abrasco é um importante documento científico interdisciplinar que apresenta os impactos dos agrotóxicos na saúde dos brasileiros. Nesse sentido ressalta-se a importância dessa pauta nas agendas políticas municipais, estaduais e federais para "a adoção de políticas de incentivo à agroecologia articulada com a reforma agrária para que o modelo químico-dependente seja alterado" (Carneiro, 2015, p. 189). O próximo tópico trata dessa alternativa para o controle de pragas e doenças sem o uso de agrotóxico.

\section{UMA ALTERNATIVA SUSTENTÁVEL: O CONTROLE AGROECOLÓGICO DE PRAGAS E DOENÇAS NA AGRICULTURA}

Como já mencionado a Revolução verde trouxe diversas consequências, dentre elas os monocultivos e consequentemente, as pragas e a introdução dos agrotóxicos nos cultivos agrícolas. Essas consequências encadeadas acontecem porque a natureza funciona em ecossistemas. Segundo Primavesi (1994) as interrelações são várias e as interdependências são grandes. Desse modo, não existe fator isolado. O fator econômico, por exemplo, não está dissociado do fator ecológico, bem como o ser humano não está dissociado da natureza. E, justamente por isso, não pode simplesmente nos afastar de suas leis, querendo dominar, modificar e explorar sem pensar que faz parte desse conjunto.

A autora menciona que a agricultura convencional disseminada em diversas partes do mundo aplica princípios que não respeitam os princípios maiores da natureza e por isso resulta em diversas consequências. Sobre isso, Altieri (1999) afirma que os agrônomos da agricultura convencional utilizam os pressupostos dominantes da ciência moderna no "fazer agricultura". Tais como o atomismo ao não considerar por exemplo que um cultivo ou a falta dele pode interferir em outro. Muitas vezes estudam as propriedades físicas do solo separadamente das propriedades biológicas e da vida que as mantém; o universalismo quando trazem por exemplo o processo de aração das terras com os mesmos equipamentos e técnicas norte americanas, não considerando que um país tropical apresenta condições distintas; o objetivismo quando supõe que a produção agrícola pode ser entendida objetivamente sem levar em consideração os agricultores e sua maneira de pensar, os sistemas sociais e o agroecossistema ao seu redor como já exemplificamos no item anterior. 
Para o autor a agronomia convencional baseada em tais princípios desenvolve de forma isolada tecnologias de nutrição vegetal e manejo de pragas e assumem que estes resultados podem ser transferidos para agricultores(as) na forma de novas tecnologias achando que tais tecnologias se encaixam em qualquer sistema agrícola.

Assim, quando se menciona o termo controle agroecológico de pragas e doenças entende-se que ele é o que Primavesi (1994) chama de manejo integrado ou manejo ecológico. Ou seja, aquele que procura o equilíbrio entre todos os conjuntos ecológicos da natureza. Para que esse manejo integrado aconteça precisamos adotar outros princípios e daí a importância da agroecologia que possui princípios distintos e que superam os da ciência e agricultura convencional.

De acordo com Altieri (1999) as premissas filosóficas da agroecologia contrastam radicalmente com as premissas dominantes, uma vez que atribui legitimidade às formas de aprendizagem e conhecimento dos agricultores. Essas premissas são o holismo que entendendo que as partes não podem ser compreendidas separadamente de seu todo e o todo é diferente da soma de suas partes, pois há uma interação permanente e transformadora entre elas, podendo desenvolver novas características ou mesmo surgir outras totalmente novas; o contextualismo já que fenômenos dependem de um grande número de determinados fatores, especialmente ligados ao tempo e ao espaço. Fenômenos similares podem ocorrer em tempos e espaços diferentes devido a fatores amplamente diferentes; o subjetivismo entendendo que os sistemas sociais e especialmente os naturais não podem ser compreendidos separadamente de nossas atividades, valores, cultura e história, ou seja, toda realidade existe a partir de um sujeito que a compreende (subjetividade). E o pluralismo, pois sistemas complexos só podem ser conhecidos através de vários padrões e formas de pensar.

O autor destaca ainda que é preciso superar a concepção de ciência como fonte única do conhecimento válido, pois os conhecimentos produzidos pelos agricultores representam importante alternativa na recuperação e manutenção ambiental ou na construção da sustentabilidade, em suas várias dimensões.

Dialogando com Ana Primavesi e com Miguel Altieri, Gliessman (2002) vai afirmar que durante a segunda metade do século XX a agricultura convencional obteve grande êxito na produção de alimentos. Esse auge se deve aos avanços científicos e tecnológicos que incluem o uso de fertilizantes, desenvolvimento de novas variedades de plantas e uso de agrotóxicos. Mas, tal êxito também provocou a degradação das bases da produtividade: solo, água e diversidade genética. Além disso, tem criado dependência do uso de recursos não renováveis 


\section{R/AS:}

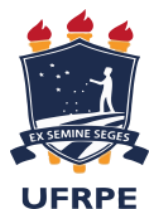

como o petróleo e fomentado um sistema que elimina a responsabilidade dos agricultores e trabalhadores do campo do processo de produzir alimentos.

Assim, esses três autores consideram que a agricultura convencional não é sustentável. A longo prazo não tem potencial para produzir alimento suficiente para a demanda populacional porque no presente está destruindo a base que a sustenta. Todas as práticas de manejo usadas na agricultura convencional tendem a favorecer a alta produtividade a curto prazo comprometendo a produtividade dos cultivos futuros. Logo, o único caminho possível quando se pensa em equilíbrio ecológico e social é através da agroecologia.

Nesse sentido, sabendo que o uso de agrotóxico faz parte dos pacotes tecnológicos da Revolução verde, não se pode pensar somente em eliminar o uso de agrotóxicos, mas mudar todo o sistema produtivo, as práticas que são empregadas e a forma de pensar agricultura. Do mesmo modo, não é possível simplesmente combater pragas e doenças por meio de defensivos naturais. Até porque como diz Primavesi (1992) “o simples combate com um ou outro método normalmente não resolve". Deve-se pensar em combate integrado e nos conjuntos de ecossistemas. Não adiantaria aplicar métodos naturais de combate às pragas em milhares de hectares de monoculturas, pois se o sistema não está em equilíbrio o problema não é resolvido. Esse é um exemplo dado constantemente pelos agricultores de Alvorada do Gurguéia.

A agroecologia é portadora de métodos naturais e/ou de controle biológico de insetos herbívoros e microorganismos potencialmente patogênicos sempre que eventuais desequilíbrios populacionais dessas espécies coloquem em risco o sucesso das lavouras (Carneiro, 2015, p. 32), mas sempre pensando no conjunto, pois como menciona Ana Primavesi o controle ecológico não procura matar a praga, mas não cria-la.

Nesse sentido, a melhor forma de combater pragas e doenças é manter o sistema em equilíbrio. E equilíbrio quer dizer que nem uma espécie é beneficiada. Todas vivem com as mesmas chances e as mesmas pressões das outras e assim são controladas. Para isso é necessário diversificação produtiva, rotação de culturas, matéria orgânica no solo, proteção da superfície do solo, processo de descompactação e arejamento do solo (Primavesi, 1994).

Em se tratando especificamente das formas de controle das pragas e doenças, Primavesi (1994) afirma que existem diversas formas de fazer um controle respeitando a natureza e as pessoas. A autora destaca quatro modos de combate e dois de prevenção. São eles, combate mecânico, físico, químico, biológico e a prevenção a partir da diversificação e da resistência vegetal por uma nutrição adequada.

Aqui destacam-se o equilíbrio e a diversificação para garantia de vida do solo, como também aumentar a resistência vegetal para uma melhor nutrição. A diversificação que trata a 

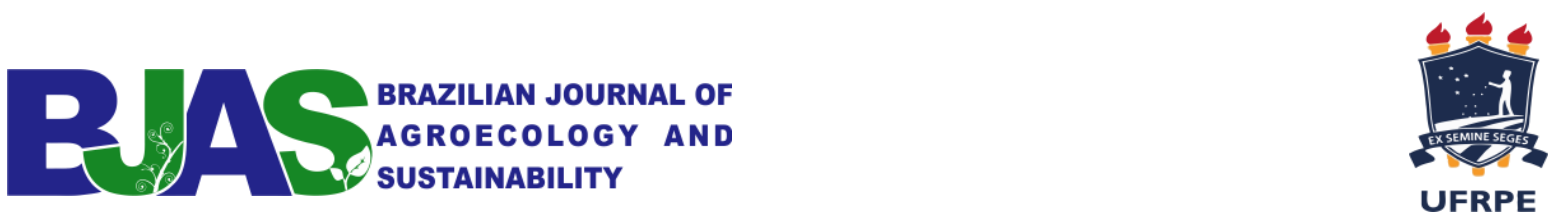

autora é o uso de policultivos ao invés de monoculturas. Quando se tem uma produção diversificada, haverá benefícios para o agroecossistema, pois em muitos casos uma planta serve de proteção para outra, por exemplo em uma horta com cebola ou o coentro deve-se plantar também hortelã, pois o cheiro forte dessa erva incomoda alguns insetos que possivelmente poderia atacar aquele canteiro com cebola e/ou coentro. Essas plantas são uma forma eficiente de combate contra pragas e doenças, já que uma protege a outra.

Não é o foco do trabalho debater as formas de controle de cada uma das pragas e doenças existentes, mas Primavesi traz essas formas na sua obra "manejo ecológico de pragas e doenças" e mostra que existem formas sustentáveis para manter o equilíbrio dos agroecossistemas sem uso de agrotóxicos e considerando as inúmeras interrelações existentes na natureza. Para isso, mais importante que conhecer técnicas alternativas de controle de pragas e doenças é mudar a forma de se fazer agricultura. Fazer uma agricultura que considere os saberes, as culturas dos povos e os princípios da natureza.

\section{AGRICULTURA E CONTROLE DE PRAGAS E DOENÇAS EM ALVORADA DO GURGUÉIA}

Toda a contextualização desde o processo de modernização da agricultura ao uso de agrotóxicos e o manejo agroecológico de pragas e doenças visa refletir sobre a realidade da agricultura em Alvorada do Gurguéia. O município teve sua origem a partir de um projeto de irrigação implantado pelo DNOCS ${ }^{3}$. Até então os agricultores que formavam o povoado não fazia uso de agrotóxico. Os agricultores relatam que enquanto o DNOCS atuava na área contavam com uma cooperativa local e certa assistência técnica em que aprendiam como usar os equipamentos, os fertilizantes e os agrotóxicos. No entanto, com a saída do DNOCS a cooperativa deixou de assistir os colonos e foi desativada.

Essa situação leva à reflexão sobre a implementação de políticas que não consideram a cultura e a realidade da população local. No caso, os agricultores não detinham conhecimento teórico e prático sobre cooperativismo, tão pouco tiveram formação suficiente para seguir com a proposta após a saída do DNOCS. O espaço está abandonado há 17 anos e de acordo com os agricultores a cooperativa foi desativada justamente por má administração, pois a diretoria era

\footnotetext{
${ }^{3}$ Segundo dados do site o DNOCS foi criado com o nome de Inspetoria de Obras Contra as Sacas (IOCS) por meio do Decreto 7.619, de 2 de outubro de 1909, ainda em 1919 por meio do decreto 13.687 recebeu o nome de Inspetoria Federal de Obras Contra as Secas (IFOCS) antes de passar a ter o nome com o qual é conhecido hoje Departamento Nacional de Obras Contra as Secas (DNOCS), que dentre os órgãos regionais se torna a Instituição Federal mais antiga completando 110 anos no ano de 2019 (DNOCS, 2013).
} 

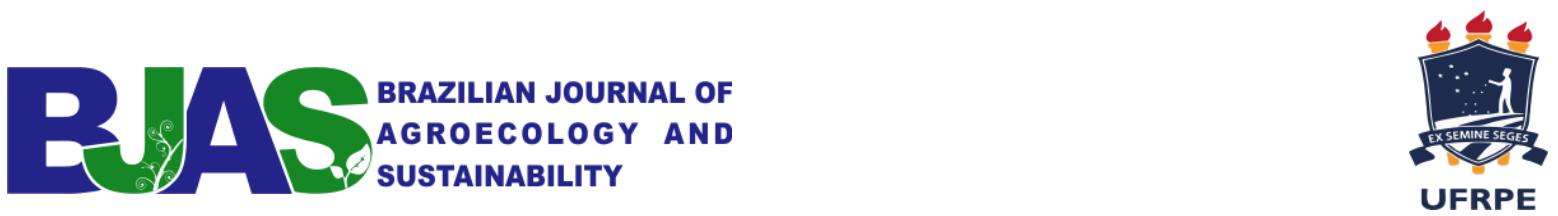

composta por agricultores colonos, muitas vezes analfabetos e acostumados a administrar somente a produção.

No que se refere a produção agrícola, os agricultores relatam que inicialmente se trabalhava com uma grande produção de arroz, mas essa produção tem reduzido cada vez mais no município. Assim, os cultivos mais produzidos atualmente são: banana, feijão, melancia, mandioca e o milho. As distancias das roças para a sede do município variam entre $2 \mathrm{~km}$ e $9 \mathrm{~km}$ o que permite que mesmo morando na cidade muitos agricultores mantenham seus cultivos.

O preparo da terra é realizado com auxílio de trator ou de forma manual. O que os agricultores produzem é direcionado para consumo da família e para venda. Algumas sementes como milho e melancia são compradas em casas agropecuárias e outras como as de feijão são armazenadas e guardadas para serem utilizadas na safra seguinte.

Essa contradição de ter sementes do agronegócio e sementes crioulas no mesmo espaço leva a duas reflexões: a) a revolução verde movida pelo capital consegue chegar em todos os espaços, até mesmo nos agricultores camponeses. Embora, não favoreça esses agricultores que continuam subordinados e dependentes desde a semente que compra até o momento da comercialização dos produtos para o atravessador. Além de muitas vezes comprometer a soberania alimentar da família quando deixa, por exemplo, o policultivo tradicional na esperança de ganhar um pouco mais com o monocultivo de melancia; b) contraditoriamente, a lógica camponesa não foi eliminada, pois ainda se mantém o trabalho familiar, o plantio para consumo, o armazenamento de sementes e, portanto, existe uma esperança de se pensar em alternativas ao modelo produtivo da revolução verde, a exemplo da agroecologia.

Alguns agricultores entrevistados relataram utilizar agrotóxico em suas plantações. Ainda que não concordem com o método de controle, alegam ser a única forma de controle que conhecem. Quando perguntados sobre a forma de aplicação, os agricultores mencionam que algumas vezes aplicam as substâncias, e ocasiões em que pagam para fazer a aplicação, como foi descrito por um dos entrevistados: "Hoje você vê pessoas pagando cinquenta reais, cem reais para um cara aplicar um dia de veneno na sua área, mas o dono mesmo não vai. O dono está preservando a vida dele e sacrificando a do outro para obter resultado".

Nesse sentido, a pesquisa evidenciou que muitos agricultores têm consciência dos riscos que a aplicação de agrotóxico oferece. Mas, contraditoriamente, nem todos utilizam equipamentos de proteção individual, e consequentemente, ficam mais expostos ao veneno, podendo sofrer uma intoxicação. 

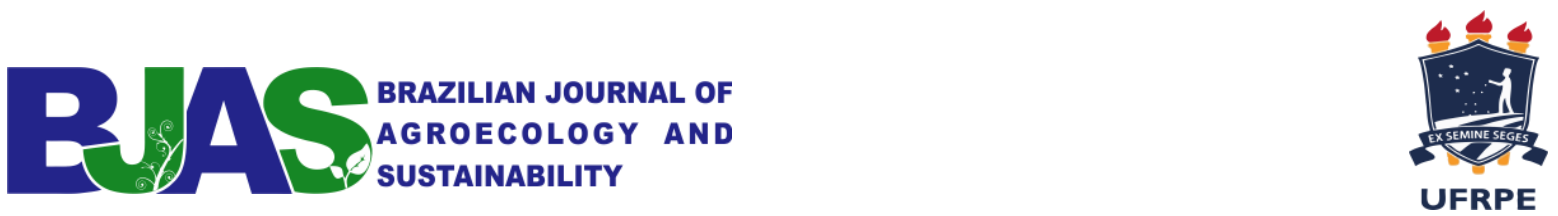

Todos os entrevistados relataram casos próximos em que após o contato com o agrotóxico, os agricultores começaram a sentir tontura, dor de barriga, náuseas e atribuem esses sintomas à aplicação do agrotóxico.

Essa situação é preocupante, pois a legislação e as empresas tentam esconder os riscos desses venenos com as noções de uso seguro ou de uso racional dos agrotóxicos. Como aponta Paulo Petersen, no Dossiê da Abrasco de 2015, além de criarem a falsa ideia de que algumas medidas preventivas acabariam com os riscos de intoxicação, o termo agrotóxico ao invés de veneno forma uma blindagem jurídica para as empresas agroquímicas que transferem a responsabilidade pelas intoxicações para as vítimas, sob a alegação de que estas não adotam os procedimentos de segurança recomendados.

O fato é que as empresas que comercializam agrotóxicos na realidade em estudo não cumprem o estabelecido na legislação e não existe uma fiscalização eficiente para garantir o cumprimento da lei. Todos os agricultores entrevistados mencionaram a facilidade para comprar os agrotóxicos. Como relatado por um entrevistado: "Eles entregam um certificado com as instruções de como aplicar e vendem para qualquer um. Até para quem não sabe ler”.

Durante as entrevistas observou-se nas propriedades rurais várias embalagens de agrotóxicos. Os entrevistados relataram que os recipientes de plástico são furados, armazenados e devolvidos para a loja. Entretanto, quando a empresa não manda recolher esses recipientes, os próprios agricultores procuram queimá-los.

Os agricultores mencionam que a situação, em relação as embalagens, era mais grave, pois como não havia conhecimento dos riscos de contaminação, as embalagens de agrotóxicos eram jogadas a céu aberto ou reutilizadas pelos agricultores para colocar água para o consumo.

Eu ainda cheguei a ver gente lavando esses baldes. De primeiro, vinha uns baldes de vinte litros de veneno, cheguei a ver gente lavando com sabão em pó e botando água para consumo dentro desses baldes, porque eles não tinham conhecimento que fazia mal. Era um plástico muito bom, um tamborzão bonito. Naquele tempo era uma carência aí tudo que a gente via aproveitava. De forma errada né. (Entrevistado 1)

Vale salientar que os resíduos presentes em embalagens de agrotóxico além de causar intoxicação nas pessoas, quando abandonados no meio ambiente ou descartados de forma inadequada, contaminam o solo e, sob as ações da chuva, são carregados para águas superficiais e subterrâneas. (Carneiro, 2015).

A Lei 9.974, de 6 de janeiro de 2000, posteriormente atualizada pelo Decreto 4.074, de 4 de janeiro de 2002 diz que é responsabilidade das empresas o destino das embalagens. No seu artigo 6 aponta: 


\section{RASS}

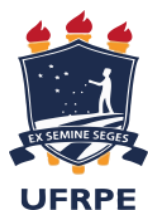

$\S 5^{\circ}$ As empresas produtoras e comercializadoras de agrotóxicos, seus componentes e afins, são responsáveis pela destinação das embalagens vazias dos produtos por elas fabricados e comercializados, após a devolução pelos usuários, e pela dos produtos apreendidos pela ação fiscalizatória e dos impróprios para utilização ou em desuso, com vistas à sua reutilização, reciclagem ou inutilização, obedecidas as normas e instruções dos órgãos registrantes e sanitário-ambientais competentes. (Brasil, 2000).

A lei é frágil porque aponta a responsabilidade das empresas após a devolução pelos agricultores. No entanto, nem sempre esses agricultores têm formação ou assistência técnica para que faça esse descarte da forma ideal. Ainda no seu capítulo 6 a lei 9.974 de 6 janeiro de 2000 determina:

$\S 2^{\circ}$ Os usuários de agrotóxicos, seus componentes e afins deverão efetuar a devolução
das embalagens vazias dos produtos aos estabelecimentos comerciais em que foram
adquiridos, de acordo com as instruções previstas nas respectivas bulas, no prazo de
até um ano, contado da data de compra, ou prazo superior, se autorizado pelo órgão
registrante, podendo a devolução ser intermediada por postos ou centros de
recolhimento, desde que autorizados e fiscalizados pelo órgão competente.

O dossiê da Abrasco traz uma crítica em relação a lei pelo fato de que ainda quando as empresas fazem cartilhas orientando sobre a devolução das embalagens, não apresentam esclarecimentos sobre a toxidade dos venenos. Do mesmo modo, ainda culpabilizam os agricultores pela poluição ambiental, alegando que os agricultores não estão seguindo a lei. (Carneiro, 2015, p. 148). Outro ponto que vale destacar é que sendo as embalagens lavadas pelos próprios agricultores o risco de contaminação é maior, devido ser mais uma forma de contato com os resíduos de veneno nas embalagens.

Quando se analisa a realidade do Piauí, o dossiê Abrasco (2015) aponta que as embalagens largadas no campo correspondem a 32,2\%; as que são queimadas/enterradas $51,8 \%$; as que são reaproveitadas $0,6 \%$; as que são descartadas como lixo comum $3,6 \%$; guardadas no estabelecimento $3,3 \%$; devolvidas ou coletas seletivas 5,5\%; outros tipos de descarte $4,6 \%$.

Esses dados são preocupantes porque mostram que no estado mais de $80 \%$ das embalagens são descartadas inadequadamente, podendo vir a provocar diversos impactos ambientais e na saúde das pessoas. Daí nota-se a necessidade de uma legislação que responsabilize mais as empresas; a necessidade de maior fiscalização e sensibilização com acompanhamento dos agricultores para fazer esse descarte de forma correta enquanto não alcançamos a utopia de um campo livre de agrotóxicos.

Durante os trabalhos de campo foi possível encontrar quantidades relevantes de agrotóxicos nas propriedades rurais. Dentre os agrotóxicos encontrados destacam-se o Actara, o Nuprid, o Applaud, e o Engeo pleno S. Essas foram as substâncias mais citadas pelos 

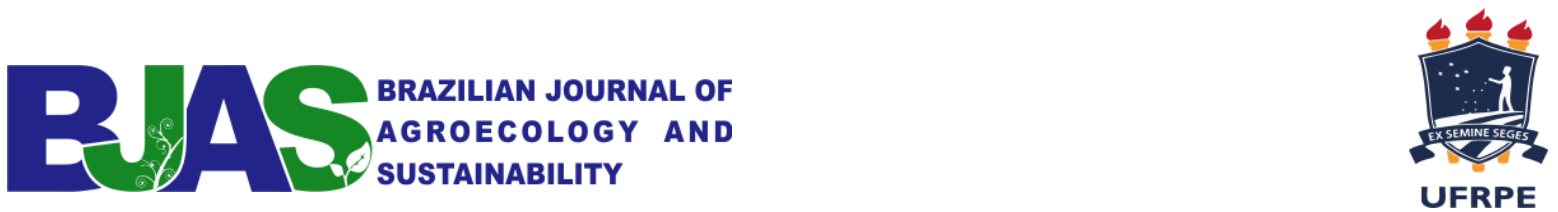

agricultores o para combate de pragas. O quadro 1 apresenta algumas informações retiradas da bula desses produtos.

Quadro 1 - Informações contidas na bula dos Agrotóxicos

\begin{tabular}{|c|c|}
\hline $\begin{array}{l}\text { Actara } 250 \\
\text { (Fabricante } \\
\text { Syngenta) }\end{array}$ & $\begin{array}{l}\text { Composição: TIAMETOXAM } 250 \mathrm{~g} / \mathrm{kg}(25 \% \text { m/m) } \\
\text { Outros ingredientes: } 750 \mathrm{~g} / \mathrm{kg}(75 \% \mathrm{~m} / \mathrm{m})\end{array}$ \\
\hline Modo de uso & $\begin{array}{l}\text { No cultivo de Melancia (combate pulgão e mosca branca): Pulverização } \\
\text { foliar: Utilizar pulverizador costal ou tratorizado com volumes de aplicação } \\
\text { de } 500 \mathrm{~L} / \text { ha. } \\
\text { No cultivo do Feijão (combate de mosca branca, cigarrinha e vaquinha): } \\
\text { iniciar as aplicações logo no início da infestação. O número de aplicações } \\
\text { depende da pressão da praga. As aplicações poderão ser repetidas até } 2 \\
\text { vezes. Evite o plantio de feijão junto a lavouras antigas de feijão ou soja. } \\
\text { Nestas condições, quando da colheita destas áreas, haverá uma migração } \\
\text { muito grande de mosca branca para a nova cultura, tornando inevitável a } \\
\text { transmissão da virose. Para evitar pulverizações excessivas na fase de } \\
\text { emergência e desenvolvimento inicial, torna-se imprescindível o tratamento } \\
\text { de sementes com um produto efetivo contra a mosca branca. Na ausência de } \\
\text { um bom tratamento de sementes ou com sementes tratadas com produtos } \\
\text { não específicos para mosca branca, poderá haver introdução da virose. } \\
\text { Nessas condições, quando houver } 60 \% \text { de plântulas emergidas, aplicar um } \\
\text { produto de contato para eliminar a população adulta migrante. Após a } \\
\text { emergência total da cultura, iniciar as aplicações de ACTARA } 250 \text { WG, com } \\
\text { intervalos de } 7 \text { dias. }\end{array}$ \\
\hline $\begin{array}{l}\text { NUPRID } 700 \\
\text { (Fabricante } \\
\text { Nufarm) }\end{array}$ & $\begin{array}{l}\text { Composição: Imidacloprido } 700 \mathrm{~g} / \mathrm{kg} \\
\text { Outros ingredientes } 300 \mathrm{~g} / \mathrm{kg}(30 \% \mathrm{~m} / \mathrm{m})\end{array}$ \\
\hline Modo de uso & $\begin{array}{l}\text { Feijão (combate de mosca branca e cigarrinha): pulverização foliar } \\
\text { usando bico cônico vazio e volume de calda de } 200 \text { a } 400 \mathrm{~L} / \mathrm{ha} \text {. }\end{array}$ \\
\hline $\begin{array}{l}\text { APPLAUD } \\
250 \\
\text { (Fabricante } \\
\text { Sipcam } \\
\text { Nichino) } \\
\end{array}$ & $\begin{array}{l}\text { Composição: BUPROFEZINA. } 250 \mathrm{~g} / \mathrm{kg}(25 \% \mathrm{~m} / \mathrm{m}) \\
\text { Outros ingredientes } 750 \mathrm{~g} / \mathrm{kg}(75 \% \mathrm{~m} / \mathrm{m})\end{array}$ \\
\hline Modo de uso & $\begin{array}{l}\text { No cultivo do Feijão e Melancia (combate de mosca branca): as } \\
\text { aplicações devem ser iniciadas quando for constatada a presença das } \\
\text { primeiras "ninfas" ou formas jovens das pragas nas culturas indicadas. No } \\
\text { controle principalmente da "mosca branca", a pulverização deve ser feita de } \\
\text { modo a atingir as formas jovens, na parte inferior das folhas. É importante } \\
\text { observar o índice populacional de "adultos". Se for alto, recomenda-se } \\
\text { aplicar um inseticida que tenha ação sobre os "adultos" e em seguida aplicar } \\
\text { Applaud } 250\end{array}$ \\
\hline
\end{tabular}




\begin{tabular}{|c|c|}
\hline $\begin{array}{l}\text { ENGEO } \\
\text { PLENO S } \\
\text { (Fabricante } \\
\text { Syngenta) }\end{array}$ & $\begin{array}{l}\text { Composição: TIAMETOXAM141 g/L }(14,1 \% \text { m/v) } \\
\text { Lambda-Cialotrina } 106 \mathrm{~g} / \mathrm{l} \\
\text { Outros Ingredientes } 872 \mathrm{~g} / \mathrm{L}(87,2 \mathrm{~m} / \mathrm{v})\end{array}$ \\
\hline Modo de uso & $\begin{array}{l}\text { No cultivo de Feijão (combate de vaquinha e larva alfinete): Utilizar } \\
\text { pulverizador costal ou tratorizado com volumes de aplicação ao redor de } 200 \\
\text { L/há }\end{array}$ \\
\hline
\end{tabular}

Fonte: Dados compilados a partir das bulas dos agrotóxicos encontrados durante a pesquisa de campo, setembro de 2019.

Os dados do quadro dialogam com todas as discussões feitas até aqui em relação ao uso dos agrotóxicos e suas consequências.

Primeiro os dados reforçam o que Larissa Bombardi traz sobre a presença de empresas multinacionais no consumo dos agrotóxicos no Brasil. Dos quatro principais agrotóxicos usados pelos agricultores dois são da Syngenta, uma empresa que teve origem na Suiça, mas que atualmente é uma empresa global presente em mais de 90 países. A Nufarm também é uma empresa global com sede na Austrália, mas que atua na Austrália, Nova Zelândia, Ásia, Europa e Américas. Por fim a Sipcam/nichino é uma fusão da empresa brasileira Sipcam com a japonesa Nichino e atuam no mercado interno brasileiro.

Em segundo lugar, quando analisamos o modo de uso notamos como é explicito a presença dos pacotes tecnológicos, ou seja a dependência que o agricultor tem para poder alcançar um melhor resultado, como no trecho "Para evitar pulverizações excessivas na fase de emergência e desenvolvimento inicial, torna-se imprescindível o tratamento de sementes com um produto efetivo contra a mosca branca." Ou ainda "É importante observar o índice populacional de 'adultos'. Se for alto, recomenda-se aplicar um inseticida que tenha ação sobre os 'adultos' e em seguida aplicar Applaud 250”.

Ainda sobre essa problemática os agricultores se dizem conscientes dos riscos, mas nem sempre leem as instruções.

Quando questionados em relação às alternativas ao uso de agrotóxicos, observou-se que nem todos os agricultores conhecem tais alternativas. Apenas um entrevistado conhece e faz defensivos com a folha do nim e outro entrevistado afirma não fazer uso de agrotóxico em sua propriedade. $\mathrm{O}$ agricultor afirma que cultiva de modo diversificado há, aproximadamente, 15 anos. Realiza manejo manual (as vezes usa trator). Os adubos utilizados são o esterco de animais, palha da carnaúba e barro/lama do rio. Afirma ainda que desconhece os defensivos naturais, pois não existem pragas em suas plantações. Ao apresentar a proposta de manejo agroecológico de pragas e doenças para os entrevistados, todos afirmaram ter interesse em conhecer mais sobre o tema e experimentar. 

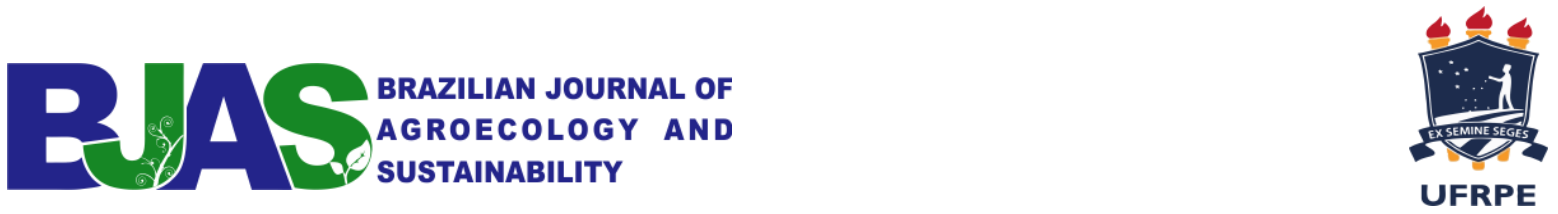

Nesse sentido, pode-se afirmar que agricultores têm conhecimento dos riscos à saúde que sofrem ao trabalhar com agrotóxicos e estão abertos à novas possibilidades, mas nota-se também que os impactos ambientais não estão claros para esses agricultores, o que exige maior incentivo às práticas agroecológicas e sensibilização em relação ao não uso dos agrotóxicos.

\section{CONSIDERAÇÕES FINAIS}

A pesquisa demonstra que a Revolução Verde no Sul do Piauí veio acompanhada de uma assistência técnica pública seguindo os motes de tal revolução sem considerar os princípios da natureza nem as culturas locais. Esse aspecto associado a falta de conhecimento sobre o controle agroecológico de pragas e doenças pelos agricultores do município de Alvorada contribuiu para a adesão e o uso de agrotóxicos no município.

Diante desse contexto percebe-se que a revolução verde movida pelo capital chega em todos os espaços e alcança os camponeses. Contudo, a lógica camponesa não foi eliminada, ainda se mantém o trabalho familiar, o plantio para consumo, o armazenamento de sementes e, portanto, uma esperança de se pensar em alternativas ao modelo produtivo da revolução verde. A pesquisa revelou que muitos camponeses fazem uso de agrotóxicos, mas desejam encontrar alternativas para substituir a utilização desses venenos. E nesse sentido, a agroecologia é posta como uma alternativa sustentável não somente para o combate das pragas e doenças, mas para todo o sistema produtivo e social.

Desse modo, pode-se afirmar que existem formas sustentáveis para manter o equilíbrio dos agroecossistemas sem uso de agrotóxicos e considerando as inúmeras interrelações existentes na natureza. Para isso, mais importante que conhecer técnicas alternativas de controle de pragas e doenças é mudar a forma de se fazer agricultura. Fazer uma agricultura que considere os saberes, as culturas dos povos e os princípios da natureza.

\section{REFERÊNCIAS}

Altieri, M (1999). Agroecologia: bases científicas para uma agricultura sustentável. Montevideo: Nordan.

Agência Nacional de Vigilância Sanitária. (2016). Relatório das análises de amostras monitoradas no período de 2013 a 2015. Brasília,DF.

Bombardi, Larissa M. (2017). Geografia do uso de agrotóxicos no Brasil e conexões com a União Europeia. São Paulo: FFLCH-USP. 

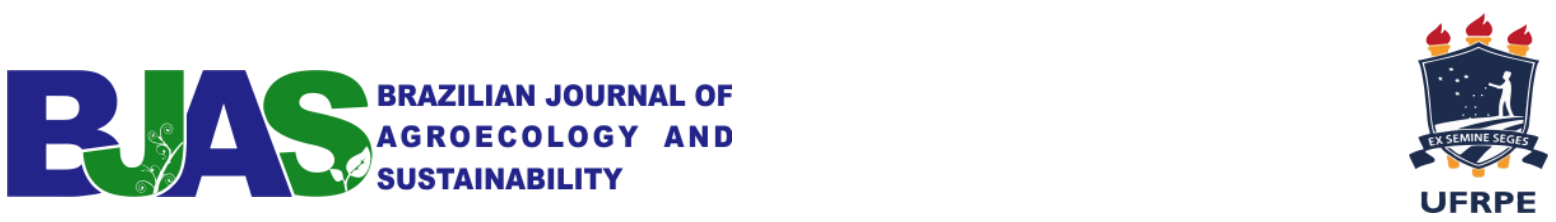

Bombardi, Larissa M. (2012). Agrotóxicos e agronegócio: arcaico e moderno se fundem no campo brasileiro. Direitos Humanos no Brasil 2012. Relatório de Rede Social de Justiça e Direitos Humanos. São Paulo.

Brasil (1989). Lei no 7.802, de 11 de julho de 1989. Diário Oficial da República Federativa do Brasil.

Brasil (2000). Lei $N^{o}$ 9.974, de 6 de junho de 2000. Diário Oficial da República Federativa do Brasil.

Cara, C. A. (2009). Modernização da agricultura brasileira e impactos ambientais. Perspectivas Geográficas - Unioeste Geografia. 1,2(5) 126-135.

Carneiro, F. F. (2015). Dossiê ABRASCO: um alerta sobre os impactos dos agrotóxicos na saúde. EPSJV/Expressão Popular.

Curvo, H. R. M.; Pignati, W. A.; \& Pignatti, M. G. (2013). Morbilidade por câncer infantojuvenil associado ao uso de agrotóxicos no Estado do Mato Grosso, Brasil. Cad. Saúde Colet., Rio de Janeiro, p. 10-17.

De Souza, G. V. A., \& Pereira, M. F. V. (2019). Matopiba: A Inteligência Territorial Estratégica (Ite) E A Regionalização Como Ferramenta/Matopiba: Strategic Territorial Intelligence And Regionalization As A Tool/Matopiba: La Inteligencia Territorial Estratégica Y La Regionalización Como Herramienta. REVISTA NERA, (47), 22-45.

De Andrade Palma, D. C., \& Lourencetti, C. (2011). Agrotóxicos em água e alimentos: risco a saúde humana. Revista Brasileira Multidisciplinar, 14(2), 7-21.

Departamento Nacional de Obras Contra as Secas. (2013). História. (23 de outubro de 2013). Recuperado em https://www2.dnocs.gov.br/historia.

Gliessman, Stephen R. (2002). Agroecologia: procesos ecológicos en agricultura sostenible. Turrialba, C.R.: CATIE.

Instituto Brasileiro de Geografia e Estatística (2019). História. Alvora do Gurguéia. Recuperado em https://cidades.ibge.gov.br/brasil/pi/alvorada-do-gurgueia/panorama.

Instituto Brasileiro de Geografia e Estatística (2017). Censo Agropecuário 2017. Recuperado em https://cidades.ibge.gov.br/brasil/pi/alvorada-do-gurgueia/pesquisa/24/75511

Instituto Nacional do Câncer. (2018). Agrotóxico. Recuperado em https://www.inca.gov.br/exposicao-no-trabalho-e-no-ambiente/agrotoxicos

Pereira, L. A., \& Sousa, R. A. D. (2016). O uso intensivo de agrotóxicos: a nova questão agrária. OKARA: Geografia em Debate. 10(1) 185-194.

Pereira, M. C. B (2012). Revolução Verde. In: Caldart, Roseli Salete; Pereira, Isabel Brasil; Alentejano, Paulo; Frigotto, Gaudêncio. Dicionário da Educação do Campo. São Paulo: Expressão Popular. p. 687-691. 

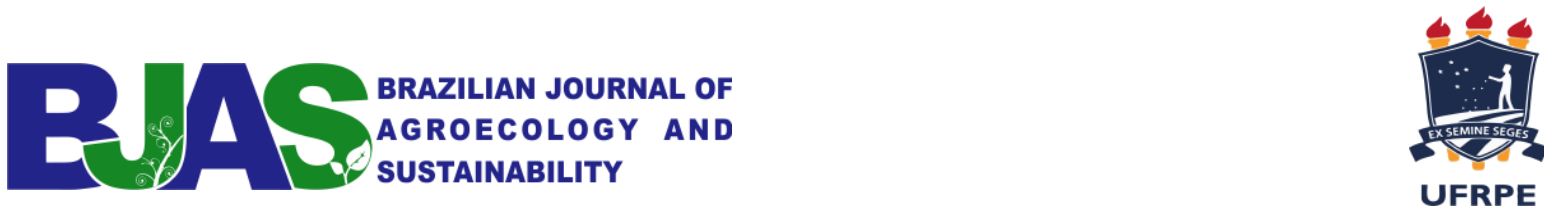

Petersen, P. (2012). Agriculturas Alternativas. In: Caldart, Roseli Salete, Pereira, Isabel Brasil, Alentejano, \& Paulo, Frigotto Gaudêncio. Dicionário da Educação do Campo. Rio de Janeiro, São Paulo: Escola Politécnica de Saúde Joaquim Venâncio, Expressão Popular.

Primavesi, A. (1992). Agricultura sustentável: manual do produtor rural, maior produtividade, maiores lucros, respeito à terra. São Paulo, Brazil: Nobel.

Primavesi, A. (1994). Manejo ecológico de pragas e doenças: técnicas alternativas para a produção agropecuária e defesa do meio ambiente. São Paulo: Nobel.

Rigotto, R. (2011). Agrotóxicos, trabalho e saúde: vulnerabilidade e resistência no contexto da modernização agrícola no baixo Jaguaribe, CE. In Agrotóxicos, trabalho e saúde: vulnerabilidade e resistência no contexto da modernização agrícola no baixo Jaguaribe, $C E$ (pp. 612-612).

Rufo. T. F. (2013). Modernização agrícola no sudoeste piauiense: impactos na rede urbana regional, no meio ambiente e nas comunidades. 2013. Trabalho de Conclusão de Curso (Graduação), Universidade Brasília, Instituto de ciências Humanas, Departamento de Geografia. Brasília- DF.

Spadotto, B. R., \& Cogueto, J. V. (2019). Avanço Do Agronegócio Nos Cerrados Do Piauí: Horizontalidades E Verticalidades Na Relação Entre O Ambientalismo Dos Pobres E O Controle De Terras Pelo Capital Financeiro/The Rush Of Agribusiness In The Cerrado Of Piauí: Horizontalities And Verticalities In The Relation Between The Environmentalism Of The Poor And The Global Land Grabbing/El Avance Del Agronegocio En El Cerrado De Piauí: Horizontalidades Y Verticalidades En La Relación Entre El Ambientalismo De Los Pobres Y El Acaparamiento De Tierras. REVISTA NERA, (47), 202-229. 